\title{
Implications of newly-formed seed-dispersal mutualisms between birds and introduced plants in northern California, USA
}

\author{
Clare E. Aslan
}

Received: 11 September 2010/Accepted: 2 February 2011/Published online: 17 February 2011

(C) The Author(s) 2011. This article is published with open access at Springerlink.com

\begin{abstract}
I examined the role of bird dispersal in invasiveness of three non-native plant species in California, USA: Triadica sebifera, Ligustrum lucidum, and Olea europaea. I selected these species because their invasiveness in California is uncertain, but a survey of ornithologists highlighted them as likely bird-dispersed. I quantified bird frugivory of these plants, compared them with a native species (Heteromeles arbutifolia), and explored the management implications of dispersal mutualisms for these and other incipient invasive plants. Fruit removal by birds was sufficient to permit spread for all study species. Seed dispersers (rather than seed predators) and pulse feeders (flocking species with potential for long distance dispersal) performed most fruit removal for the non-native species, a pattern indicative of an effective dispersal regime. The number of fruiting trees per stand was a significant predictor of bird visitation. Founding population size may thus be important in management of invasive, bird-dispersed plants. Disperser-defined niches were relatively
\end{abstract}

Electronic supplementary material The online version of this article (doi:10.1007/s10530-011-9966-1) contains supplementary material, which is available to authorized users.

C. E. Aslan $(\square)$

Environmental Studies Department, University of California, Santa Cruz, 1156 High Street, Santa Cruz, CA 95064, USA

e-mail: caslan@ucsc.edu narrow because a few disperser species performed the majority of fruit removal from study trees, but each fruit species was consumed by a variety of potential dispersers. This results in strong pairwise niche overlap between some plant species. Ordinated by bird use, study site-species combinations clustered more by geographic location than by plant species, emphasizing the opportunistic nature of bird foraging. None of the non-native focal plant species appears dispersal limited, and all have formed novel mutualisms in California. It is possible that these plants are now in lag phases preceding bird-mediated invasion. Consideration of bird dispersal when evaluating invasiveness is therefore an imperative.

Keywords Bird-mediated dispersal - Focal individual observations · Frugivory · Mutualisms . Niche $\cdot$ Risk assessment

\section{Introduction}

When plant species are introduced to new environments, their interactions with resident organisms may determine whether or not they become invasive (Richardson et al. 2000). Non-natives can be limited by competition with or herbivory by resident species (Cogni 2010; Corbin and D'Antonio 2004; Naeem et al. 2000). On the other hand, positive interactions such as mutualisms with dispersers, pollinators, or 
soil biota may permit invasion of new environments (Bascompte and Jordano 2007; Reinhart and Callaway 2006). Furthermore, such mutualisms are generally diffuse, with many mutualist species interacting with each plant species (Aslan and Rejmánek 2010; Bascompte and Jordano 2007; Jordano 1987b). For this reason, many introduced plants with fleshy fruits are able to develop effective dispersal interactions with resident fauna (e.g., Bartuszevige and Gorchov 2006; Drummond 2005; Gosper et al. 2005; Panetta and McKee 1997; Renne et al. 2002). Plant species unable to form novel dispersal mutualisms with new partners in their region of introduction may have greatly reduced potential for invasive spread (Gosper et al. 2005). Bird-mediated dispersal is therefore a trait that many rubrics associate with plant invasiveness (Pheloung et al. 1999; Pyšek and Richardson 2007; Rejmánek 2000; Rejmánek et al. 2005).

Mutualistic bird dispersal confers a number of advantages to the dispersed species. Bird-mediated dispersal removes seeds from the immediate neighborhood of the parent tree, possibly separating seeds and seedlings from natural enemies and often depositing them in suitable recruitment sites (Connell 1971; Gosper et al. 2005; Janzen 1970; Wenny 2001). Long-distance dispersal events may greatly increase the overall spread rate of a dispersed species (Nathan 2006). Seeds passing through bird guts receive mechanical and chemical treatments that sometimes promote germination (Gosper et al. 2005; Traveset 1998). Additionally, because their dispersal is assisted, fleshy-fruited seeds can often be larger than wind-dispersed seeds, enabling them to carry energy stores that enhance survival over a variety of environmental conditions (Leishman et al. 2000).

Among bird-dispersed plants, species cover a spectrum of mutualism efficiency: on one extreme, plants produce many more fruits than are removed by bird dispersers, while on the other, nearly all available fruits are removed (Herrera 1984; Renne et al. 2000). A number of factors may influence bird visitation to fruiting plants. Small fruits and seeds appear to be removed and dispersed more effectively than large fruits (Gosper et al. 2005; Rey et al. 1997). Birddispersed seeds are often contained in fruits that are bright or bicolored (Wheelwright and Janson 1985; Whelan and Willson 1994). Birds prefer accessible over inaccessible fruits (Whelan and Willson 1994) and select between trees based on fruit abundance, preferring trees with large crop sizes (Korine et al. 2000; Sallabanks 1993). Nutritional quality may attract birds to fruits of certain species (Levey and Martínez del Rio 2001). Overall density of fruits in the neighborhood also appears to promote increased bird foraging (Kwit et al. 2004; Sargent 1990).

In a questionnaire distributed to ornithologists in California, Washington, New York, and Florida, consumption by birds was reported for fruits of 17 non-native species that had not yet been explored in invasion biology literature for invasiveness in the relevant states (Aslan and Rejmánek 2010). This list pinpointed information gaps: if questionnaire respondents were correct and birds are using the plants, the plants have a ready-made dispersal mechanism and should be examined for habitat compatibility, reproductive potential, and growth rate. If no barriers to establishment exist, the plants may be "sleeper" species in the lag phase preceding invasion (Groves 1999).

I chose three of these species for empirical examination of bird-mediated dispersal in California. The selected plants, Olea europaea, Ligustrum lucidum, and Triadica sebifera, are all winter-fruiting but differ in fruit type, size, and color. They are commonly planted in urban and agricultural areas in California's Sacramento Valley. Furthermore, all three are problematic, bird-dispersed invasives elsewhere in the world, in habitats similar to those found in the Californian study region. It is therefore likely that these species will establish in Californian habitats if a dispersal vector is present. However, none of the three species has yet shown more than localized spread in California. Since questionnaire results indicated that Californian birds do use the fruits of these plants, I hypothesized that the plants are in lag phases and likely to be incipient invaders, facilitated by birds, in the region.

I conducted an observational study to examine the degree to which birds have integrated the plants into the regional bird-plant community. I gathered parallel information for Heteromeles arbutifolia, which is the only widespread, simultaneously-fruiting native species that co-occurs with the study species in both urban and rural sites in the region. I asked two primary questions, within which were nested several secondary questions: (1) Do bird visitation and fruit removal indicate that birds have the potential to disperse study species sufficiently to enable spread 
across the landscape? Specifically, (a) what proportion of fruits of each study species are removed by birds? (b) How much fruit foraging may be attributed to birds of different behavioral and feeding guilds? (2) What are the implications of bird use of these species for management of these and other incipient, bird-dispersed invaders? Specifically, (a) what characteristics of local site and fruiting stands contribute to bird visitation and fruit removal from non-native trees? (b) Is dispersal attributable to one or a few primary dispersers that could be considered in management for invasion by these species, or is it highly diffuse? (c) How much disperser-defined niche overlap exists between study species and the native species?

\section{Methods}

\section{Study species}

\section{Olea europaea}

Originating in the Mediterranean basin, European olive (Olea europaea L., Oleaceae) was introduced to California in the late 1700s (Connell 2004). The tree is widespread in California today, mostly in orchards or windbreaks. Fruits are large drupes, deep purple to black at maturity, each containing a single seed with a very hard testa.

Olea europaea fruits are dispersed effectively by birds in the Mediterranean (Rey and Alcántara 2000) and in Australia, where O. europaea is invasive in natural areas (Spennemann and Allen 2000b). Abandoned $O$. europaea groves in Australia are now seed sources for naturalizing populations dispersed by birds; a lag phase of approximately 200 years occurred prior to the invasion (Besnard et al. 2007; Spennemann and Allen 2000a). Feral stands have dense, long-lived canopies under which heterospecific trees can rarely establish (Spennemann and Allen 2000a).

\section{Triadica sebifera}

Chinese tallow (Triadica sebifera (L.) Small or Sapium sebiferum (L.) Roxb., Euphorbiaceae) is native to eastern Asia and has been planted for the past 40 years in northern California as an ornamental landscaping tree. The species has become highly invasive in the southeastern U.S., where it infests large floodplain, wetland, and low-lying forest areas, enriching soil and forming monocultures that displace native species (Bruce et al. 1997; Cameron and Spencer 1989; Jubinsky and Anderson 1996). Fourteen bird species in the invaded region have been shown to consume $T$. sebifera seeds (Renne et al. 2000). Fruits are capsules that dehisce with maturity to reveal 2-3 round seeds, each encased in a white, waxy aril.

Although T. sebifera's moisture requirements exclude it from colonizing California's dry uplands, climate modeling predicts that the species will successfully establish in the state's highly-threatened riparian areas (Pattison and Mack 2008). Current spread into natural areas has been observed at a small number of riparian sites in northern California (Bower et al. 2009), but widespread and rapid invasion has not yet occurred. Since a substantial lag phase passed prior to invasion in the Southeast (Bruce et al. 1997), it is logical that the species may be exhibiting a similar delay before greater invasiveness in California (Bower et al. 2009).

\section{Ligustrum lucidum}

Glossy privet (Ligustrum lucidum W. T. Ait., Oleaceae), native to Asia, is a problematic invader in Florida, Japan, Australia, New Zealand, and Argentina (Aragón and Groom 2003; Dehgan 1998; Hashimoto et al. 2005; Panetta 2000) and an emerging invader in South Africa ( $\mathrm{Nel}$ et al. 2004). Fruits are blue-black berries, smaller than those of the other study species, and borne in panicles with dozens to hundreds of fruits per infructescence. Individual tree fruit loads can be very large (e.g., 3 million fruits for an individual in moist conditions in Australia) (Swarbrick et al. 1999). While L. lucidum generally invades areas with abundant or elevated soil moisture (Hashimoto et al. 2007; Panetta 2000; Swarbrick et al. 1999) and is therefore probably limited in California to riparian zones, it can grow in a broad range of light, temperature, and soil conditions (Aragón and Groom 2003; Lichstein et al. 2004; Swarbrick et al. 1999). It dominates shrub and small tree strata in invaded regions (Panetta 2000). Soil fertility and understory light penetration were decreased and native sapling mortality increased where L. lucidum had invaded in Argentina 
(Lichstein et al. 2004). The tree's dense, shallow root system depletes soil nutrients and water (Swarbrick et al. 1999).

Birds effectively disperse L. lucidum in its invaded regions. In Argentina, 11 resident bird species were observed eating L. lucidum fruits, with some birds acting as dispersers and others as seed predators (destroying seeds through crushing or other damage) (Montaldo 1993). In Australia, L. lucidum and its congener, L. sinense, represented three-quarters of the diet of native pied currawongs (Strepera graculina) during the fruiting season (Spennemann and Allen 2000b). Seventeen bird species were observed utilizing $L$. lucidum for various purposes in New South Wales, where the species has replaced extirpated native food sources (Ekert and Bucher 1999).

While L. lucidum has been observed spreading in certain localities in California (S. Mason, pers comm), its overall naturalized distribution and spread at the state level are unknown (DiTomaso and Healy 2007). The species is common in urban, irrigated areas throughout central and southern California, planted as a landscaping and hedge species.

\section{Heteromeles arbutifolia}

Toyon (Heteromeles arbutifolia Lindl., Rosaceae) is native to California and was utilized as a comparison species for all analyses. Although it differs from nonnative study species in fruit color (red vs. purple, purple-black, and white) and growth form (tall shrub vs. short tree), it is the only native fleshy-fruited plant growing in all study sites and fruiting simultaneously with non-native study species. It grows as a shrub or small tree and is common in chaparral and mixed oak woodland communities (Hickman 1993). Fruits are round, bright-red pomes, borne in panicles of dozens to hundreds at the tips of branches; each plant can produce tens to hundreds of thousands of fruits per year (pers. obs.).

\section{Study sites}

I selected multiple, geographically distant study sites (treated as blocks in statistical analyses) for observations of each study species (Fig. 1). In all, six study sites were utilized in three counties (Butte, Yolo, and Sacramento). Because not all study species occurred in all study sites, each of the four plant species was examined in at least three and not more than four of these sites (Fig. 1). Observations were conducted on a total of 12 stands of each species. I employed at least three stands per site-species combination, except for O. europaea in the Big Chico Creek Ecological Reserve, of which only two stands exist.

All study sites were located in the Sacramento River Valley of California, between $38^{\circ} 27^{\prime} \mathrm{N}$ and $39^{\circ} 53^{\prime} \mathrm{N}$. The region is characterized by a mediterranean climate, receiving the large majority of its precipitation during the cool winter months. Agricultural fields, broken by urban pockets and remnant riparian corridors, dominate the valley. The abundance of agriculture provides ample food for wildlife and may be partially responsible for the high winter bird diversity (approximately 170 species) found in the region (Engilis 1995). Higher elevation regions at the valley's edges support chaparral and oak-grassland habitats.

Because two study species (T. sebifera and L. lucidum) are thus far largely restricted to urban zones where they have been planted, four of the six study sites were urban areas: Sacramento, Davis, Woodland, and Chico. Focal stands (3 or more reproductive individuals in close proximity) of study species were selected in urban parks and greenbelts.

The two rural study sites had stands of $O$. europaea and $H$. arbutifolia (Fig. 1). The first of these was the Putah Creek riparian zone between the city of Davis and the coast range foothills. This site included fallow agricultural fields and chaparral sites adjacent to riparian vegetation. The second rural site was the Big Chico Creek Ecological Reserve (BCCER), located in the chaparral- and oak-dominated foothills of the northern Sierra Nevada, upstream from the city of Chico.

Bird removal and consumption of study species fruits

Fruit traps: mutualism efficiency (overall proportion of fruits removed)

To estimate the proportion of fruits removed by bird foragers, I placed fruit collection traps beneath study tree canopies. Traps were large buckets of heavy plastic, $38 \mathrm{~cm}$ in diameter, covered with concave Bird Block ${ }^{\circledR}$ netting with $1 \mathrm{~cm}^{2}$ mesh size to prevent vertebrate entry (for $O$. europaea, since fruits are 
Fig. 1 Map of study sitespecies combinations. Study sites were located in Butte, Yolo, and Sacramento Counties in the Sacramento River Valley, California. A total of 12 study stands, distributed among 3-4 sites, were used for each plant species. Circles and italicized abbreviations identify study sites on the map as follows:

BCCER = Big Chico Creek Ecological Reserve; $\mathrm{C}=$ Chico;

$\mathrm{W}=$ Woodland;

$\mathrm{PC}=$ Putah Creek

watershed;

$\mathrm{S}=$ Sacramento;

$\mathrm{D}=$ Davis. Each circle is divided into four segments and shaded to indicate which study species were present and utilized in that site. Upper left quadrant indicates Heteromeles arbutifolia; upper right quadrant indicates Triadica sebifera; lower right quadrant indicates Olea europaea; lower left quadrant indicates Ligustrum lucidum

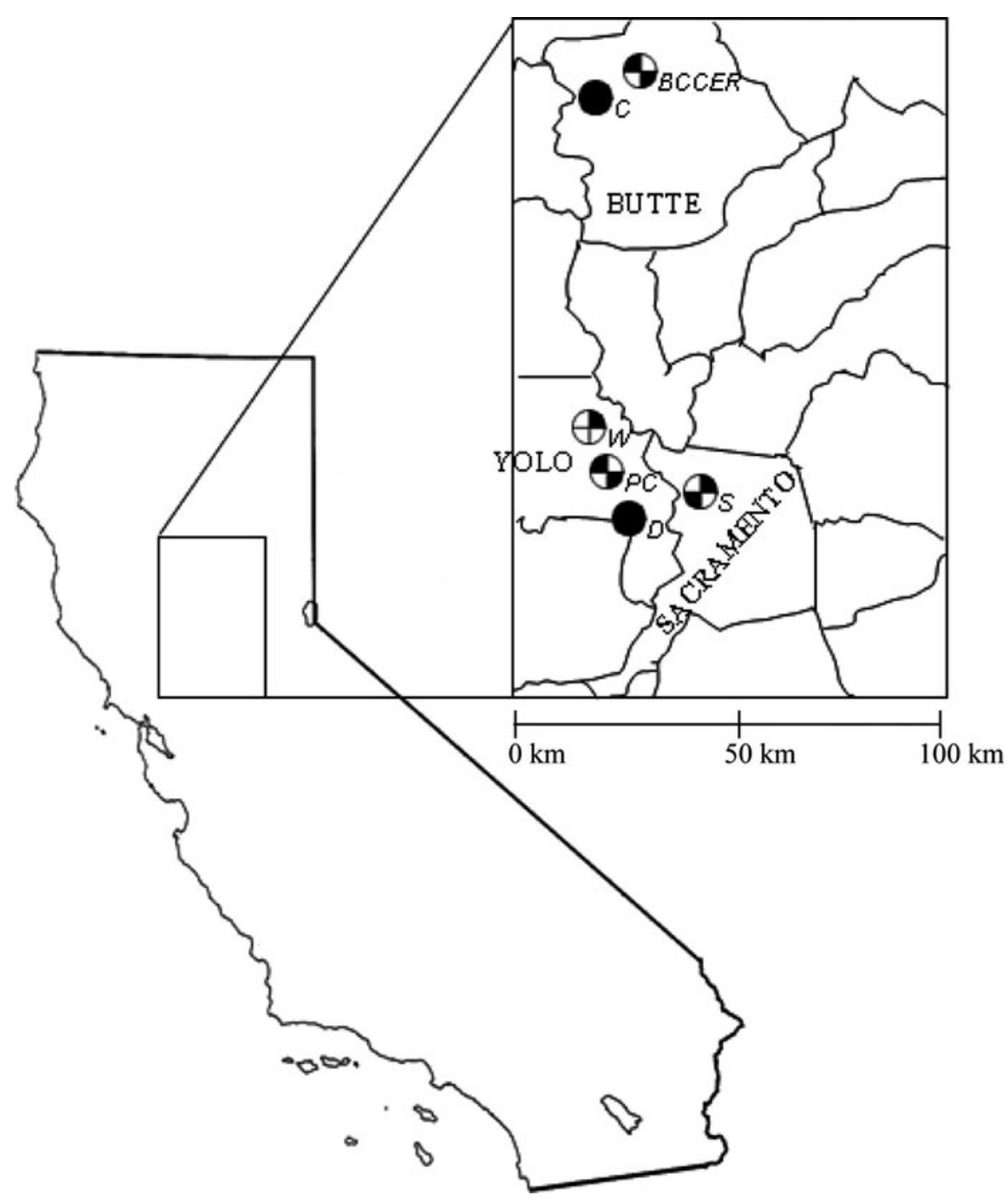

larger, I instead used concave hardware cloth with $2 \mathrm{~cm}$-width openings). Holes at the bottom of the buckets permitted rainwater to exit, but were covered with screen to keep seeds inside. Each trap was anchored with two pieces of $1.2 \mathrm{~m}$ rebar, driven $45 \mathrm{~cm}$ into the ground and connected to the trap with zip-ties. Two traps were placed on the ground under randomly-selected trees at each of four stands in two sites per study species, for a total of 32 sampled trees. In trap placement, the outer trap edge was aligned directly beneath the outer edge of the tree's canopy. Traps remained in place throughout the fruiting season until all ripe fruits had fallen or been removed from the tree by bird foragers. Traps were checked weekly to ensure that they remained in place and that their mesh covers were undisturbed.
To estimate the total fruit load of sampled trees, I measured the tree canopy diameter and counted the fruits in the canopy slice formed by a random 1-m arc of the tree's perimeter, then extrapolated over the full tree. I treated each tree canopy as a hollow cone, measuring the diameter of the inner, fruit-free region surrounding the tree's trunk and calculating the volume of the fruit-bearing canopy as the difference between the total canopy cone volume and that inner cone volume. Canopy height was measured with a clinometer. The sampled volume of the canopy was the proportion of the total fruit-carrying region that was directly above each trap. I used this proportion to generate an expected number of fruits in the region above each trap. The difference between that expected number and the count of fruits in the trap at the end of 
the season was my estimate of the number of fruits removed by birds. This method addresses a daunting challenge: to estimate the proportion of fruit removed by birds in a tree producing hundreds of thousands of fruits. Since trees are non-uniform in fruit distribution and since wind, rain, and other factors can shift the angle of seed rain, error may be high for this or any other method of fruit fate assessment. By using two traps per tree (placed on opposite sides of the tree's trunk), I was able to calculate average estimated numbers of fruits removed for each tree and to examine standard error to evaluate the degree of agreement between the two trap results.

While almost all foraging on $H$. arbutifolia, L. lucidum, and T. sebifera fruits occurred in the trees themselves, a large proportion of the foraging observed on $O$. europaea took place on fallen fruits on the ground beneath trees. To explore the proportion of O. europaea fruits taken by birds, I therefore included a ground removal estimate, as follows: at the beginning of the fruiting season, I used $0.6 \mathrm{~m}$ rebar to mark a circle on the ground adjacent and equivalent in diameter to each O. europaea fruit trap. I cleared these circles of $O$. europaea seed remnants from previous seasons. At the end of the studied fruiting period, I counted the number of intact $O$. europaea seeds in that circle and compared that quantity with the number of fruits captured in the fruit trap. In all cases, a much smaller number of seeds was found in the circle than in the trap; the difference provided an estimate of the proportion of fruits that were removed by vertebrate foragers (either birds or ground-foraging mammals) after falling from the tree.

\section{Foraging observations (focal individual and scan sampling)}

Focal individual observations and scan sampling (modified from Farwig et al. 2006) were combined to quantify visitation and fruit removal by birds at 12 stands of each study species. Observations were conducted in two fruiting seasons: November 2007-March 2008, and November 2008-March 2009. For each observation period, the stand and time of day were selected at random with each stand observed on at least 3 separate occasions during the course of each season (and, each season, at least once each at sunrise and sunset). I continued to select stands for observation until no more fruits remained on study trees. In all, $97.5 \mathrm{~h}$ of observations were conducted on O. europaea, $108 \mathrm{~h}$ on L. lucidum, $96 \mathrm{~h}$ on T. sebifera, and $105 \mathrm{~h}$ on H. arbutifolia.

Because most bird foraging occurs at dawn and dusk, observations were restricted to those periods. Exploratory visits to study stands at other times during the day found minimal or no bird activity. Sunrise observations began 15 min prior to sunrise, while sunset observations began $75 \mathrm{~min}$ prior to sunset. Each observation period lasted $90 \mathrm{~min}$ and was divided into nine 10-min periods. For the first minute of each period, an observer conducted scan sampling from a predetermined point, noting all bird species and the number of individuals of each species in the visible trees of the stand during that minute. For the remaining 9 min of each period, the observer conducted focal individual observations, selecting individuals haphazardly and following each selected individual with binoculars, counting the number of fruits swallowed, dropped, pecked, and taken in flight (meaning that the bird carried the fruit away in its beak and ingestion was not observed) until the individual flew away or until $120 \mathrm{~s}$ had elapsed. The observer recorded the total time that each individual was observed, then selected another individual. When possible, the observer selected a new species each time; if this was impossible, a new member of an observed species was selected.

When calculating rates of fruit removal, I combined counts of fruits swallowed and of fruits taken in flight to generate a total estimate of fruits dispersed per focal individual (after Renne et al. 2000). I calculated the rate of dispersal as the number of fruits dispersed per individual per minute per tree, averaged across all observations on that stand. A Type 1 ANOVA determined that Year was not a significant predictor of fruit removal, so I pooled the information from the two study years to generate final fruit dispersal rates for each species. Repeated observations of the same sample trees were treated as subsamples and averaged to estimate rates of fruit removal from those trees by each bird species.

To compare the dispersal importance of each bird species for each plant species, I calculated Flock Dispersal Importance (FDI) and Overall Dispersal Importance (ODI) after Renne et al. (2000) for all bird-plant species combinations. FDI is the product of the average per-individual fruit dispersal rate and the average number of individuals per species (i.e., flock 
size) detected per tree during scan sampling; it provides an estimate of dispersal importance per foraging bout of a given bird species. ODI is the product of FDI and the number of observations in which that species was detected foraging in observed trees; it takes into account the number of flocks per species over the full study, distinguishing between common and rare interactions.

I distinguished two bird guilds defined by flocking and territorial behavior. "Pulse feeders" was the label I assigned to birds that visited fruiting plants in large foraging flocks, moving over the landscape between stands and visiting each for a brief portion of the fruiting season (resulting in a heavy but short-lived pulse of fruit removal). "Background feeders," on the other hand, displayed resident territoriality and were present in stands in constant but low numbers throughout the fruiting season. Fruit-handling guilds included "dispersers" that swallowed fruits and likely defecated or regurgitated many of them whole and "seed predators" that destroyed most seeds during feeding or are known from physiological studies to destroy seeds after swallowing them. Since dispersal of fruits by predators occurs far less than does predation, I calculated FRI (Fruit Removal Importance) instead of FDI and ORI (Overall Removal Importance) instead of ODI for predators.

Implications for management

\section{Stand description}

A multiple linear regression with sequential (type I) tests, with plant species as a covariate, was used to determine which stand and site characteristics are predictive of bird visitation rates (averaged across all bird species) within each plant species. Data were log-transformed to meet MLR assumptions. Statistical analysis was performed in JMP version 5.0.1 (SAS Institute). Significance was accepted at $P \leq 0.05$. The following characteristics were measured: number of conspecifics in the stand, total stand area, distance to water, average height, basal diameter and dbh of stand trees, average distance between conspecifics in the stand, distance to the nearest road or path, estimated number of fruits per stand, and site-specific estimate of frugivore density (obtained through variable-plot distance sampling). Because the total number of samples was low (48) relative to the variable list, we used coefficients of determination to guide model selection. Our final model included plant species as covariate and number of conspecific individuals, average plant height, and their interaction as independent variables.

To evaluate the effect of different sites (with, presumably, differing avian communities) on bird visitation rates, I conducted variable-plot distance sampling at all six study sites to estimate frugivorous bird densities. I conducted point counts at 70 random points per study site. Each point was separated from other points by at least $200 \mathrm{~m}$. Point counts lasted 7 min. During each count, I recorded all birds seen and heard and measured the distance from the point to each bird using a Nikon laser rangefinder. Estimates of bird densities were then obtained using the program Distance (Thomas et al. 2010), which employs a likelihood function to account for missed detections. I used ANOVA to determine whether estimated frugivore densities were predictive of bird visitation.

\section{Niche overlap analysis and ordination}

Niche analyses and ordination enabled me to explore the form and function of study species membership in the regional bird-plant community. Quantification of niche breadth and overlap allows assessment of an organism's functional specialization, as well as its relationships with related or functionally similar species (Hutchinson 1957; Whittaker et al. 1973). Such metrics are usually employed with reference to dietary or spatial requirements, although Grubb (1977) discussed the importance of dispersal and other aspects of regeneration in niche definition. I applied niche quantification methods in a new fashion by identifying avian frugivores as the niche-defining resource and basing niche calculations on that resource. Frugivore-defined niche breadth indicates whether these plants rely upon a few key mutualists (implied by low niche breadth values) versus dispersal by a broader range of species (i.e., greater evenness). Niche overlap measures the similarity in resource use (in this case, use of avian dispersers) displayed by focal species (Krebs 1999). Species with greater overlap likely compete more for avian dispersers than those with low overlap. Overlap quantification allowed me to consider the implications of widespread occurrence of these non-native 
species in the ecological community. I then employed canonical correspondence analysis (CCA) to examine bird use of study plants over space, time, and broadscale habitat types. The resulting triplot offered a visual depiction of the frugivore-defined community position in the study area.

To perform niche and ordination analyses, I used ODI and ORI values for each bird-plant species combination. Levins's measure of niche breadth $\left(B=1 / \sum p_{j}^{2}\right)$, where $p_{j}=$ the proportion of individuals found in or using resource state $j$ or, in this context, the proportion of each plant's total ODI/ORI that was attributable to each bird species, quantifies niche breadth in order to assess the degree to which each plant specializes on certain disperser species (after Krebs 1999). Levins's measure is standardized with the formula

$B_{A}=\frac{B-1}{n-1}$

where $B_{A}=$ standardized niche breadth, $B=$ Levins's measure of niche breadth, and $n=$ the number of possible resource states. Here, I considered the number of possible resource states to be equal to the number of bird species observed dispersing fruits over the course of the study; a similar technique has been used to apply Levins's measure to assess mutualist-defined niche breadth in pollinator relationships (Kephart 1983). Application of this metric in this way assumes that all four of my focal plant species had access to the same number of potential disperser species (i.e., that the same total (across all sites) suite of potential frugivores was present for all plants). Although this assumption may be imperfect, I pooled fruit removal data for each plant species across its 12 study stands to generate the speciesspecific numbers used here. Data for each plant species are therefore derived from 3 to 4 different geographic sites and include sites where the different study species occur in close proximity to one another.

To assess niche overlap among all pairs of study plants (a total of six comparisons), I utilized percentage overlap (Abrams 1980; Schoener 1970), which is calculated by the formula

$P_{j k}=\left[\sum_{i=1}^{n}\left(\min p_{i j}, p_{i k}\right)\right] \cdot 100$

where $p_{j k}=$ percentage overlap between species $j$ and $k, p_{i j}=$ proportion disperser species $i$ performed of the total dispersal recorded for species $j, p_{i k}=$ proportion disperser species $i$ performed of the total dispersal recorded for species $k$, and $n=$ total number of resource states. I utilized proportional comparisons instead of direct counts of fruits swallowed because the study fruits differ so substantially in size.

Ordination by CCA (Lepš and Šmilauer 2003) enabled me to visually examine niche separation and assess the influences of time, space, and plant species on the bird community's use of study fruits. These analyses were performed in CANOCO 4.5 (ter Braak and Šmilauer 2002) with default options. Broad habitat designations (urban, riparian, or chaparral) were included as nominal environmental variables for each site-study species combination. These environmental variables were tested for significance using 499 unconstrainted Monte Carlo permutations. I treated individual stands as subsamples and unique site-plant species combinations as samples. To assess shifting bird communities over the winter, I separated early (through January) and late winter foraging data and compared the two resulting ordination diagrams. To minimize the effect of outliers, only those birds that visited at least two stands or for which ODI/ORI was $\geq 5.0$ were included in this analysis. Habitat categories occur as centroids in the resulting triplots.

\section{Results}

Bird removal and consumption of study species fruits

Fruit traps: estimated proportion of fruits removed by birds

Averaged across sampled trees, the proportion of fruits removed by birds from native $H$. arbutifolia was $0.94 \pm 0.02$ SE. For L. lucidum the estimated proportion of fruits removed was $0.77 \pm 0.13 \mathrm{SE}$, and for T. sebifera, the proportion was $0.24 \pm 0.15$ SE. For $O$. europaea, the proportion removed before fruit fell from trees was $0.27 \pm 0.12 \mathrm{SE}$. The ground removal assessment estimated that the proportion of O. europaea fruits removed directly from the ground after falling from the tree was $0.45 \pm 0.04$. Applying the tree removal proportions to all fruit loads in the study stands, I calculated an average total number of 
fruits removed by birds per tree for each study species (Table 1).

For each study tree, the two seed traps were in strong agreement. The largest standard error of the mean of any trap pair was 0.05 , and the majority of standard errors were less than 0.01 .

\section{Foraging observations (focal individual and scan sampling)}

In all, 15 bird species consumed T. sebifera fruits, 13 species consumed L. lucidum fruits, 13 species consumed $O$. europaea fruits, and 10 species consumed native $H$. arbutifolia fruits (Online Resource 1). For non-native plants, pulse feeders and potential dispersers took disproportionately more fruits than background feeders or seed predators; that is, pulse and disperser species were a minority of visitors but responsible for a majority of frugivory. Potential dispersers took $96.3 \%$ of $T$. sebifera fruits while seed predators took $3.7 \%$. Pulse feeders took $73.6 \%$ of T. sebifera fruits. However, of the bird species that took fruits from T. sebifera, just $27 \%$ were pulse feeders (Table 2). For L. lucidum, potential dispersers took $67.1 \%$ of fruits and pulse feeders took $53.7 \%$. Meanwhile, pulse feeders accounted for just $23 \%$ and dispersers $62 \%$ of bird species that took fruits from L. lucidum (Table 2). For O. europaea, potential dispersers took $96.5 \%$ of fruits and pulse feeders $75.9 \%$. Pulse feeders accounted for only $46 \%$ and dispersers $69 \%$ of the species taking O. europaea fruits (Table 2).

For the native $H$. arbutifolia, by contrast, pulse feeders took only $48.6 \%$ of fruits, slightly less than background feeders, which took $51.4 \%$. By handling guild, results were more similar to those encountered for non-native plants: dispersers took $94.7 \%$ of H. arbutifolia fruits. Pulse feeders accounted for $30 \%$ and dispersers for $60 \%$ of all species that took fruits from $H$. arbutifolia (Table 2).

Implications for management

\section{Stand description}

The number of conspecific plant individuals per study stand was significantly and positively related to the rate of bird visitation $\left(F_{(1,37)}=20.31 ; P<0.0001\right)$. Frugivorous bird densities, estimated through variable-plot distance sampling, were not significantly related to bird visitation, nor were any other stand characteristics.

\section{Niche measurements and ordination}

Niche breadths were fairly consistent across all study species. Olea europaea exhibited the smallest niche breadth $\left(B_{A}=0.04\right)$, followed by $T$. sebifera $\left(B_{A}=0.09\right)$. Niche breadth was largest for H. arbutifolia $\left(B_{A}=0.12\right)$, but $L$. lucidum was a close second $\left(B_{A}=0.11\right)$.

Percentage overlap placed the plant species into two groups defined by actual disperser suite similarity (Table 3). Similarity emerged for $H$. arbutifolia and L. lucidum $\left(p_{j k}=41.18 \%\right.$ ) and for O. europaea and T. sebifera $\left(p_{j k}=61.06 \%\right)$. Although they belong to the same family, O. europaea and L. lucidum displayed little similarity $\left(p_{j k}=4.99 \%\right)$.

Table 1 Total estimated numbers of seeds removed by birds from study stand trees

\begin{tabular}{llccc}
\hline Study species & $\begin{array}{l}\text { Prop. fruits } \\
\text { removed }\end{array}$ & $\begin{array}{l}\text { Avg. est. no. fruits } \\
\text { per tree (fruit load) }\end{array}$ & $\begin{array}{l}\text { Avg. est. no. seeds } \\
\text { removed per tree }\end{array}$ & $\begin{array}{l}\text { Minimum no. seeds removed } \\
\text { from a sampled tree }\end{array}$ \\
\hline Heteromeles arbutifolia & $0.94 \pm 0.02$ & $105,983 \pm 48,842$ & $298,872 \pm 137,733$ & 11,118 \\
Ligustrum lucidum & $0.77 \pm 0.13$ & $712,820 \pm 211,124$ & $1,097,742 \pm 325,130$ & 38,610 \\
Triadica sebifera & $0.24 \pm 0.15$ & $38,462 \pm 8,800$ & $9,230 \pm 2,112$ & 7,666 \\
Olea europaea & $0.27 \pm 0.12$ & $10,642 \pm 3,686$ & $2,873 \pm 1,619$ & 1,486 \\
\hline
\end{tabular}

Proportions of fruit removed were estimated by ground-anchored fruit collection traps placed beneath sample trees. Fruit loads were estimated for representative trees in each stand and then averaged across all stands of each study species. Numbers of fruits were multiplied by average number of seeds per fruit to obtain total estimated number of seeds removed. Numbers are means \pm 1 standard error 
Table 2 Summary of estimated removal of study species fruits by birds of different behavioral guilds

\begin{tabular}{|c|c|c|c|}
\hline Plant species & FG & HG & ODI/ORI \\
\hline \multirow[t]{4}{*}{ Triadica sebifera } & Pulse & Dispersers & $29.41 \pm 7.38$ \\
\hline & Background & Dispersers & $9.05 \pm 1.92$ \\
\hline & Pulse & Seed predators & None \\
\hline & Background & Seed predators & $1.48 \pm 0.38$ \\
\hline \multirow[t]{4}{*}{ Ligustrum lucidum } & Pulse & Dispersers & $275.94 \pm 48.86$ \\
\hline & Background & Dispersers & $68.44 \pm 8.73$ \\
\hline & Pulse & Seed predators & None \\
\hline & Background & Seed predators & $169.17 \pm 20.74$ \\
\hline \multirow[t]{4}{*}{ Olea europaea } & Pulse & Dispersers & $116.61 \pm 34.86$ \\
\hline & Background & Dispersers & $34.33 \pm 11.59$ \\
\hline & Pulse & Seed predators & $2.10 \pm 0.00$ \\
\hline & Background & Seed predators & $3.37 \pm 1.19$ \\
\hline \multirow[t]{4}{*}{ Heteromeles arbutifolia } & Pulse & Dispersers & $98.57 \pm 19.56$ \\
\hline & Background & Dispersers & $93.4 \pm 11.48$ \\
\hline & Pulse & Seed predators & None \\
\hline & Background & Seed predators & $10.81 \pm 5.54$ \\
\hline
\end{tabular}

$\overline{\mathrm{FG}}=$ feeding guild. $\mathrm{HG}=$ handling guild. Total ODI/ORI = overall dispersal importance (for dispersers) and overall removal importance (for seed predators). Total ODI/ORI $=\sum$ (the average number of fruits removed per minute per tree $\times$ the number of observations in which the bird species was present in observed trees), summed across all bird species in these guilds. Per-species ODI, number of observations, and average flock size are available in Online Resource 1

CCA triplots ordinated each site-plant combination (as samples) with respect to the bird ODI values specific to that combination (Fig. 2a, b). For data collected during the first half of each winter, environmental variables were not significant. The triplot for fruit removal during early winter demonstrated samples clustering more by site than by plant type (Fig. 2a). Thus, samples from Chico, Putah Creek, and the BCCER tended to cluster in the upper and left portions of the triplot, associated with riparian and chaparral birds including hermit thrushes, purple finches, and spotted towhees (Fig. 2a). Most samples

Table 3 Niche overlap values calculated for study species pairs using percentage overlap

\begin{tabular}{llc}
\hline Species A & Species B & Percentage overlap (\%) \\
\hline Heteromeles & Olea & 4.41 \\
Heteromeles & Triadica & 23.04 \\
Heteromeles & Ligustrum & 41.18 \\
Ligustrum & Olea & 4.99 \\
Ligustrum & Triadica & 21.64 \\
Olea & Triadica & 61.06 \\
\hline
\end{tabular}

Only genus names are provided; species are Heteromeles arbutifolia, Olea europaea, Triadica sebifera, and Ligustrum lucidum from Davis, Sacramento, and Woodland clustered in the lower center of the triplot, associated with urban birds including house finches, European starlings, American crows, and yellow-rumped warblers. The

Fig. 2 Triplots presenting results of canonical correspondence analysis. Samples are indicated with large black circles and are ordinated with respect to their use by avian foragers (small gray triangles), with habitats as nominal environmental variables (centroids as large black triangles). Sample label code letters indicate plant species $(\mathrm{H}=$ Heteromeles arbutifolia $; \mathrm{O}=$ Olea europaea $; \mathrm{T}=$ Triadica sebifera $; \mathrm{L}=$ Ligustrum lucidum). Sample label code numbers indicate study site (1 = Davis; 2 = Sacramento; 3 = Woodland; $4=$ Chico; $5=$ Putah Creek; $6=$ Big Chico Creek Ecological Reserve). Only bird species that consumed at least two samples or had total ODI/ORI $>5$ were included in these analyses. a CCA of samples ordinated by avian use during early winter (November-January). b CCA of samples ordinated by avian use during late winter (February-March). Bird abbreviations: AMCR = American crow; $\mathrm{AMRO}=$ American robin; $\mathrm{CAQU}=\mathrm{Cali}-$ fornia quail; CEWA = cedar waxwing; DEJU = dark-eyed junco; EUST = European starling; GCSP = golden-crowned sparrow; HETH = hermit thrush; HOFI = house finch; $\mathrm{NOFL}=$ northern flicker; $\mathrm{NOMO}=$ northern mockingbird; NUWO = Nuttall's woodpecker; PUFI = purple finch; SPTO = spotted towhee; WCSP = white-crowned sparrow; WEBL = western bluebird; WITU = wild turkey; WSJA = western scrub-jay; YRWA = yellow-rumped warbler 
first axis of the ordination explained $10.6 \%$ of the variation and the second axis $8.1 \%$.

The late winter ordination reflected the same tendency for samples to cluster more by site than by plant species (Fig. 2b). Here, the environmental variable "chaparral" was significant $(P=0.002)$. Samples from sites with a high percentage of chaparral habitat, including the BCCER and Putah Creek, clustered at the right end of the X-axis, associated with chaparral birds including wild turkeys, California quail, and purple finch. Remaining samples clustered on the left end of the x-axis, associated with urban and riparian birds including American robins, American crows, house finches, and

(a)

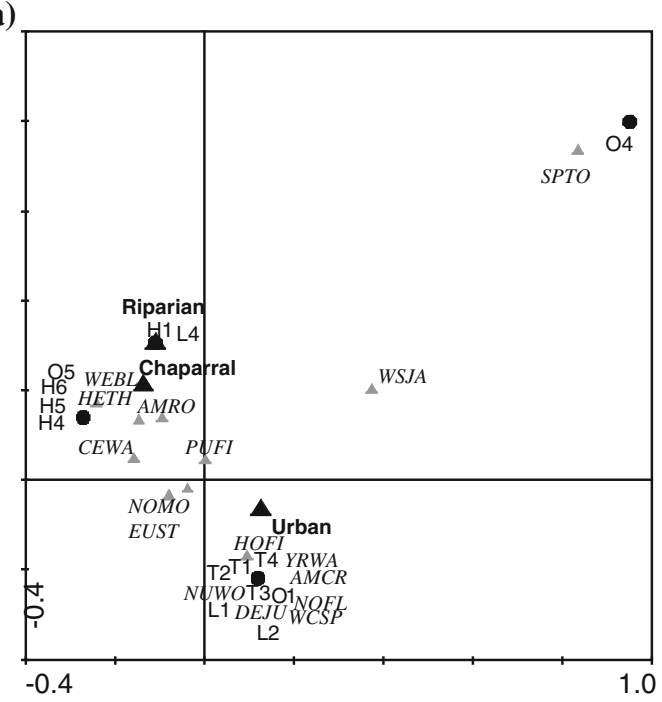

(b)

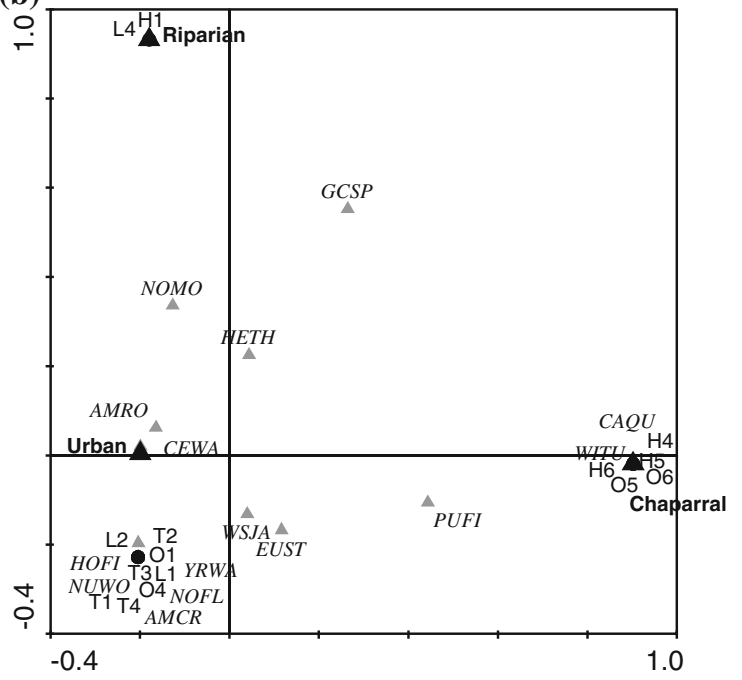

Nuttall's woodpeckers. The first axis of this ordination explained $25.4 \%$ of the variation and the second axis $4.3 \%$.

\section{Discussion}

Primary question 1: do bird visitation and fruit removal indicate that birds have the potential to disperse study species sufficiently to enable spread across the landscape?

In spite of considerable variation among them, fruits of all three non-native plant species were removed by birds at rates that, given the large fruit load per individual, could easily facilitate spread through the landscape (i.e., thousands of fruits taken per plant over the course of the season). The fruits of native H. arbutifolia were removed at the highest rate. This is consistent with observations from an ecological community in Argentina where native fruits were taken by frugivorous birds at higher rates than nonnative fruits (Montaldo 2000), although contrasting results were found in North Carolina (Greenberg and Walter 2010). Winter-fruiting non-natives in my study region compete for frugivores primarily with $H$. arbutifolia and each other. Evidently, H. arbutifolia is a strong competitor for dispersers. However, where $H$. arbutifolia is absent (such as urban settings where it is uncommon in landscaping), non-native species monopolize cold-weather bird frugivory and bird-mediated dispersal.

Published data from other regions allows comparison of the mutualism efficiency observed here with that occurring in the native landscape for $O$. europaea and in invaded regions for L. lucidum and T. sebifera. In Spanish shrublands, birds took $94 \%$ of available O. europaea fruits during a low-fruiting year and 52\% during a high-fruiting year (Jordano 1987a). In Argentina, an estimated $60 \%$ of L. lucidum fruits were taken by birds (Montaldo 2000). In invaded regions of South Carolina, birds removed $40 \%$ of the available T. sebifera crop (Renne et al. 2000). Since the value obtained here for $L$. lucidum exceeds published reports, I conclude that this species likely receives sufficient dispersal in California to permit its spread. The fruit removal value that I obtained for O. europaea was $50 \%$ below the lower value observed in Spain. This may result largely from the large fruit 
sizes of $O$. europaea planted in landscaping and hedgerows in California (sampled fruits from my study stand averaged $15.09 \mathrm{~mm}$ in width) as compared with the smaller fruits typical of wild O. europaea in Spanish shrublands (width averaging $8 \mathrm{~mm}$ ) (Jordano 1987a). Because gape width constrains bird frugivory of large fruits (Wheelwright 1985), the total number of species capable of handling larger-fruited O. europaea is likely to be smaller than those utilizing smaller-fruited O. europaea. Notably, the ground removal assessment I performed for O. europaea after noticing a high rate of bird foraging from the ground beneath trees suggested that more fruits are likely removed from the ground than directly from trees. The fruit handling behavior (frequently selecting and then dropping fruits that were too large) associated with ground removal provides further support for the hypothesis that fruit size may be largely responsible for the low rate of in-tree feeding. If ground removal and tree removal are combined, the proportion of total fruits removed for O. europaea is well within the range observed in Spain.

For T. sebifera, I observed $40 \%$ lower fruit removal than was reported for South Carolina. This may stem from T. sebifera's unusual fruit (white in color, waxy rather than fleshy) and lack of winter foliage combined with the notably high variety of fruiting species in the Sacramento Valley in the winter. As a major agricultural region, the Sacramento Valley has an abundance of both food crops and fruiting landscaping species throughout the winter, offering birds a wide array of options that may appear more attractive than T. sebifera. At least some successful dispersal of T. sebifera occurs, however, as indicated by volunteer seedlings that have been found in several watersheds (pers. obs.). Furthermore, water-mediated dispersal can facilitate population growth and spread around new reproductive individuals in riparian areas (Bower et al. 2009). Therefore, while this species may receive a lower incidence of bird-mediated dispersal than the other two study species, it does not appear that dispersal limitation is sufficient to block its invasion of riparian areas.

By guild, the large majority of fruit removal for all three non-native study species was done by potential dispersers and pulse feeders. This pattern is conducive to long-distance dispersal events. Most swallowed fruits will endure disperser handling and gut passage without being destroyed. The prevalence of pulse feeding relative to background feeding has implications for dispersal distance. Pulse feeders move over the landscape in large flocks, visiting each stand in turn and consuming most of the fruits before moving to another food patch (pers. obs.). They generally roost elsewhere, traveling to the day's target stand to feed in the mornings and evenings. Background feeders, on the other hand, exhibit territorial behavior and are present in each stand throughout the day (pers. obs.); most likely roost in or near the stand, defending their territory from conspecifics. Because pulse feeders move much greater distances between roosts and feeding sites than do background feeders, those fruits consumed by pulse feeders are more likely to experience long-distance dispersal than are those consumed by background feeders. For each stand in each season, I observed a low and fairly constant level of frugivory by background feeders until pulse feeders arrived. Pulse feeders then removed fruits at a high rate for a brief period (a few days). After the pulse feeders departed, the remaining fruits (generally less than $20 \%$ ) were taken at the low background feeding rate once more until the fruits were exhausted or the frugivory season passed.

The non-native European starling (Sturnus vulgaris) had the highest overall dispersal importance (ODI) for T. sebifera and O. europaea. Starlings are among the most adaptable birds on the planet, establishing successfully on six continents and maintaining large flocks in many habitats. It is unsurprising that they incorporate $T$. sebifera (unusual among study region fruits in color and texture) and $O$. europaea (unique in size) into their diets. Correspondingly, the relatively lower incidence of consumption of these fruits by native birds may be attributable to unfamiliarity (for T. sebifera) or size constraints (for $O$. europaea). Starlings are notably associated with disturbed habitats: they were abundant in urban and agricultural areas in this study, but during the non-nesting season are rare in more natural areas (BCCER and parts of the Putah Creek watershed). Spread by starlings of $T$. sebifera and O. europaea into natural areas is therefore likely uncommon at present.

Flock dispersal importance (FDI) allows direct quantitative comparison of the bird dispersal observed here with that recorded for $T$. sebifera in the southeastern U.S. (Renne et al. 2000). The suite of birds present in the Southeast differs somewhat 
from those found in my study region, and those birds responsible for the highest rates of fruit removal in the Southeast do not occur in the Sacramento Valley (i.e., boat-tailed grackle, Quiscalus major, and fish crow, Corvus ossifragus). However, after eliminating from consideration birds that do not occur in both sites, the species with the top three FDI values in the Southeast are identical to those with the top three FDI values in this study: S. vulgaris, Turdus migratorius (American robin), and Colaptes auratus (northern flicker). Since $T$. sebifera has become a major environmental problem in the Southeast, its use by several of the same birds bolsters its likelihood of becoming invasive in California.

Primary question 2: what are the implications of bird use of these species for management of these and other incipient, bird-dispersed invaders?

\section{Stand characteristics}

Although a number of stand characteristics were measured to test the effect of localized site traits on bird visitation, only the number of conspecifics in the stand was significant: within each species, the total number of plants offering the same fruit resource appears to be a strong attractant to birds. This result is supported by recent modeling of the role of patch size in invasive species control when long-distance dispersal events are regular occurrences (Minor and Gardner 2011). My conclusion that number of fruiting trees is important also complements previous data showing that the total number of fruits in the neighborhood is significantly and positively related to greater levels of bird foraging on exotic species (Sargent 1990). The importance of large stands has management implications: non-native fruiting trees planted in large groups are more likely to be visited by avian dispersers than are single trees or mixedspecies plantings. Managers seeking to eliminate problematic plants should consider the number of trees per stand and be aware that larger stands may be more responsible for long-distance, bird-mediated dispersal than are smaller stands.

Notably, this result suggests management strategies that conflict with Moody and Mack's (1988) recommendation that satellite populations of invasive species should be prioritized for removal in order to reduce overall spread rate. Behavior and preference of the dispersing agent may thus generate different long-distance dispersal dynamics for bird-dispersed species than arise for non-bird-dispersed species.

\section{The bird-plant community: frugivore specialization and overlap}

The majority of fruit consumption for each nonnative plant species is performed by a limited number of bird species (pulse feeders with the largest flocks), as evidenced by small niche breadths. However, these mutualisms should still be considered diffuse since many birds perform at least some consumption and likely some dispersal for each plant. As the ordination plots emphasize, birds evidently utilize these species opportunistically, clustering more by habitat than by plant type: that is, they forage in accessible and local trees rather than displaying strong, landscape-scale attraction toward particular species. The key management implication of this pattern is that birds are likely to increasingly utilize non-native plants as they spread across the landscape due to elevated encounter rate. As visitation to such plants increases, birdmediated spread rates are likely to grow in turn.

Introduction of non-native, bird-dispersed plants has the potential to impact native plants through competition for dispersers (Traveset and Richardson 2006). When the introduced species are still limited in their distribution as in the case of these study species, however, it is difficult to directly measure this competition: disperser populations are unlikely to be limiting, and the native and non-native plants are largely separated geographically. I quantified niche overlap to assess the likelihood that such competition will arise. Greatest niche overlap occurred between $O$. europaea and $T$. sebifera and between $H$. arbutifolia and L. lucidum. Among the non-native case study plants, L. lucidum therefore appears to have the greatest potential to compete with $H$. arbutifolia. The two species likely share many of the same dispersers and both exhibit high dispersal efficiency. As L. lucidum arrives in riparian areas, it will likely emerge from its lag phase through its demonstrated mutualisms with native birds. Greater densities of L. lucidum could reduce dispersal of $H$. arbutifolia.

Comparing early and late winter fruit consumption, the most notable difference is a strong shift in some of the most important disperser species from 
chaparral-dominated to urban sites. American robins, cedar waxwings, northern mockingbirds, and hermit thrushes all occurred more in chaparral-based observations during the first half of the winter, and were more likely to appear in urban sites during the second half of the winter. All of these native birds visit $H$. arbutifolia early in the season and often strip those plants of fruit before foraging on heterospecific fruits from the same site (pers. obs.). Half of sampled $H$. arbutifolia plants were in chaparral habitats; this probably accounts for the early-season association of these birds with those habitats. Later in the season, as natural area fruits become exhausted, the birds move across the landscape in response to food availability in other sites. It is during this late-season foraging that native birds are most likely attracted to urban environments where a variety of non-native fruits are consistently present; birds thus may exhibit altered movement patterns as a result of non-native plant availability.

Since fruit availability is maximal at the beginning of winter, before any stands have been heavily depleted, it may be due simply to a sampling effect that a larger number of bird species coexists at any given site during this period than later in the season (because plants can support a greater number of individual birds). A similar pattern was observed when seasonal shifts in bird populations were directly examined in Pennsylvania: both diversity and densities declined in late winter, and the authors attributed the pattern to depleted food resources contributing to higher mortality and movement of birds to artificial feeders (Rollfinke and Yahner 1990).

\section{Implications for riparian habitats}

Since habitats invaded by T. sebifera and L. lucidum elsewhere in the world are wetter than upland California, human unassisted spread for both species in this region should be limited to riparian areas. While this eliminates a large proportion of the landscape, conservation concern remains substantial. Riparian areas are highly endangered in California, with less than $10 \%$ of the original riparian forest remaining in the study region (Hunter et al. 1999). At the same time, riparian areas with intact plant communities are critical habitat for a number of species, including special status and threatened taxa such as the valley elderberry longhorn beetle and
Swainson's hawk (Brode and Bury 1984; Lang et al. 1989; RHJV 2004). Furthermore, remnant forest patches throughout the study region are often concentrated along waterways. As birds are likely to utilize these corridors for cover, nesting, and foraging, bird-mediated dispersal of non-native species may concentrate in riparian habitats. The rates of seed removal for T. sebifera and L. lucidum suggest that dispersal may be common, indicating a high likelihood of incipient invasion of riparian areas by these species. Long-distance bird-mediated dispersal into riparian zones may create far-flung foci of new populations (Moody and Mack 1988), around which gravity- and water-assisted dispersal can lead to local population growth and spread.

\section{Conclusion}

While the observations reported here were confined to three non-native plant species, results are relevant to the broader realm of bird-dispersed introduced species. Study species fruits differed greatly in type and appearance, yet all were visited and consumed in abundance by birds. Ornithologist reports thus correctly identified non-native plants that have formed mutualisms with native species (Aslan and Rejmánek 2010). The bird guilds removing the greatest numbers of fruits from all three non-native species were dispersers and pulse feeders, providing a ready mechanism for dispersal to natural areas. Since this was true for such contrasting species, the inclusion of bird-mediated dispersal as a blanket risk factor in many invasiveness prediction rubrics appears valid.

Ordination results highlight the opportunistic nature of bird feeding on both native and non-native fruits: rather than tracking specific fruit types over the landscape, birds appeared to visit multiple fruiting species in each locale. There were no detectable barriers that might impede dispersal of new nonnatives introduced into the community.

The significance of number of fruiting individuals as a driver of bird visitation indicates that birds use broad-scale assessments of the landscape to make foraging decisions. That is, rather than distinguishing among patches by actual density of fruits, birds are attracted to the trees themselves. This is logical when considering the importance to dispersal of large flocks (pulse feeders) flying from roost to feeding 
sites; it seems reasonable that a bird in flight uses broad-scale instead of fine-scale cues to direct its landing. Managers may reduce bird dispersal of unwanted species by removing clustered individuals. Since native fruits were removed at particularly high rates in this study and share many avian foragers with L. lucidum in particular, planting of native fruiting species, as has been suggested elsewhere (Gosper et al. 2005; Gosper and Vivian-Smith 2009), might be another management technique that could reduce spread of non-native seeds by creating competition for dispersers. However, this strategy requires more direct study: it is also conceivable that increasing the density of native fruiting trees at a given site will lead to an increase in the total concentration of frugivorous birds at that site, and that those birds will then consume and disperse at an enhanced rate all fruiting species, native and non-native, in the site.

All three non-native species studied here have been assimilated into local bird diets and demonstrate evidence of effective dispersal regimes in the study area. The results of these observations therefore support the hypothesis that these species may be in lag phases and possess the necessary components for future invasion in the region. Research examining germination and actual seedling performance in Californian habitats for each of these species would clarify whether barriers at other life stages might impede invasion. For T. sebifera, these barriers have been examined and none appeared operational alongside waterways (Bower et al. 2009); in combination, that study and the results presented here present strong evidence that $T$. sebifera is a likely incipient invader in California. Similar barrier examination should now be undertaken for $O$. europaea and L. lucidum.

Acknowledgments I acknowledge M. Rejmánek for essential advice and assistance and for excellent mentorship throughout this research. Feedback from M. Holyoak, T. Hahn, and three anonymous reviewers enabled me to improve the manuscript substantially. M. Chinoraks and H. Jones helped with numerous data collection and fieldwork tasks, and R. Boothby, S. ChinShar Chu, P. Epanchin, Z. Kuspa, N. Rujanavech, E. Smith, A. Aslan, M. Bower, and G. Darin assisted with observations. R. Klinger, T. Schoener, and N. Willits provided invaluable advice on data analyses. The parks and recreation departments of Davis, Chico, and Sacramento allowed me to place fruit traps on their lands. I am deeply grateful to the Big Chico Creek Ecological Reserve, the Putah Creek Riparian Reserve, and the Yolo Audubon Society for allowing a variety of research activities on their properties and providing access to facilities and resources. This research was supported by a Montana State Center for Invasive Plant Management Seed Money Grant award and a research grant from the UC Davis Biological Invasions IGERT (NSFDGE\#0114432). I was supported by a National Science Foundation Graduate Research Fellowship throughout this research. Thanks to S. Mason for study site advice, to J. Ellsworth for trap design ideas, and to O. J. and G. A. MacMillan for greatly facilitating many overnight field trips.

Open Access This article is distributed under the terms of the Creative Commons Attribution Noncommercial License which permits any noncommercial use, distribution, and reproduction in any medium, provided the original author(s) and source are credited.

\section{References}

Abrams P (1980) Some comments on measuring niche overlap. Ecology 61:44-49

Aragón R, Groom M (2003) Invasion by Ligustrum lucidum (Oleaceae) in NW Argentina: early stage characteristics in different habitat types. Rev Biol Trop 51:59-70

Aslan CE, Rejmánek M (2010) Avian use of introduced plants: ornithologist records illuminate interspecific associations and research needs. Ecol Appl 20:1005-1020

Bartuszevige AM, Gorchov DL (2006) Avian seed dispersal of an invasive shrub. Biol Invasions 8:1013-1022

Bascompte J, Jordano P (2007) Plant-animal mutualistic networks: the architecture of biodiversity. Ann Rev Ecol Evol Syst 38:567-593

Besnard G, Henry P, Wille L, Cooke D, Chapuis E (2007) On the origin of the invasive olives (Olea europaea L., Oleaceae). Heredity 99:608-619

Bower MJ, Aslan CE, Rejmánek M (2009) Invasion potential of Chinese tallowtree (Triadica sebifera) in California's Central Valley. Invasive Plant Sci Man 2:386-395

ter Braak CJF, Šmilauer P (2002) CANOCO reference manual and CanoDraw for Windows user's guide: software for canonical community ordination. Microcomputer Power, Ithaca

Brode JM, Bury RB (1984) The importance of riparian systems to amphibians and reptiles. In: Warner RE, Hendrix KM (eds) California riparian systems: ecology, conservation, and productive management. University of California Press, Berkeley, pp 30-36

Bruce KA, Cameron GN, Harcombe PA, Jubinsky G (1997) Introduction, impact on native habitats, and management of a woody invader, the Chinese tallow tree. Sapium sebiferum (L.) Roxb. Nat Areas J 17:255-260

Cameron GN, Spencer SR (1989) Rapid leaf decay and nutrient release in a Chinese tallow forest. Oecologia 80:222-228

Cogni R (2010) Resistance to plant invasion? A native specialist herbivore shows preference for and higher fitness on an introduced host. Biotropica 42:188-193

Connell JH (1971) On the role of natural enemies in preventing competitive exclusion in some marine mammals and in rainforest trees. In: den Boer PJ, Gradwell GR (eds) Dynamics of populations. Centre for Agricultural Publishing and Documentation, Wageningen, pp 298-312 
Connell JH (2004) History and scope of the olive industry. In: Sibbett GS, Ferguson L, Coviello JL, Lindstrand M (eds) Olive production manual, 2nd edition, publication 3353. University of California Agriculture and Natural Resources, Oakland, pp 1-10

Corbin JD, D'Antonio CM (2004) Competition between native perennial and exotic annual grasses: implications for an historical invasion. Ecology 85:1273-1283

Dehgan B (1998) Landscape plants for subtropical climates. University Press of Florida, Gainesville

DiTomaso JM, Healy EA (2007) Weeds of California and other western states: vol. 2 Geraniaceae-Zygophyllaceae. Publication 3488. University of California Agriculture and Natural Resources, Oakland

Drummond BA (2005) The selection of native and invasive plants by frugivorous birds in Maine. Northeast Nat 12: 33-44

Ekert PA, Bucher DJ (1999) Winter use of large-leafed privet Ligustrum lucidum (Family: Oleaceae) by birds in suburban Lismore, New South Wales. P Linn Soc NSW 121: 29-37

Engilis A Jr (1995) Valley habitats, number 6: wildlife resources of the Central Valley, California birds-part II: winter residents and transients. Ducks Unlimited Western Regional Office, Sacramento

Farwig N, Bohning-Gaese K, Bleher B (2006) Enhanced seed dispersal of Prunus africana in fragmented and disturbed habitats? Oecologia 147:238-252

Gosper CR, Vivian-Smith G (2009) Approaches to selecting native plant replacements for fleshy-fruited invasive species. Restor Ecol 17:196-204

Gosper CR, Stansbury CD, Vivian-Smith G (2005) Seed dispersal of fleshy-fruited invasive plants by birds: contributing factors and management options. Div Dist 11:549-558

Greenberg CH, Walter ST (2010) Fleshy fruit removal and nutritional composition of winter-fruiting plants: a comparison of non-native invasive and native species. Nat Areas J 30:312-321

Groves RH (1999) Sleeper weeds. In: Bishop AC, Boersma M, Barnes CD (eds) 12th Australian weeds conference. Tasmanian Weed Society Inc., Hobart, pp 632-636

Grubb PJ (1977) The maintenance of species-richness in plant communities: the importance of the regeneration niche. Biol Rev 52:107-145

Hashimoto Y, Hattori T, Ishida H, Toi K (2005) The alien plant Ligustrum lucidum escaping from planting sites to indigenous vegetation in Japan. J Jpn Ins L Arch 68:713-716

Hashimoto Y, Nakamura A, Takeda Y (2007) Effect of floods on the expansion of the alien tree glossy privet (Ligustrum lucidum Ait.) population in urban riparian environments-a case study along the Inagawa River, Hyogo Prefecture, western Japan. Jpn J Conserv Ecol 12:103-111

Herrera CM (1984) A study of avian frugivores, bird-dispersed plants, and their interaction in Mediterranean scrublands. Ecol Monogr 54:1-23

Hickman JC (ed) (1993) The Jepson manual. Higher plants of California. University of California Press, Berkeley

Hunter JC, Willett KB, McCoy MC, Quinn JF, Keller KE (1999) Prospects for preservation and restoration of riparian forests in the Sacramento Valley, California, USA. Environ Manag 24:65-75
Hutchinson GE (1957) Concluding remarks. CSH Symp Quant Biol 22:415-427

Janzen DH (1970) Herbivores and the number of tree species in tropical forests. Am Nat 104:501-528

Jordano P (1987a) Avian fruit removal: effects of fruit variation, crop size, and insect damage. Ecology 68:1711-1723

Jordano P (1987b) Patterns of mutualistic interactions in pollination and seed dispersal: connectance, dependence asymmetries, and coevolution. Am Nat 129:657-677

Jubinsky G, Anderson LC (1996) The invasive potential of Chinese tallow-tree (Sapium sebiferum Roxb.) in the southeast. Castanea 61:226-231

Kephart SR (1983) The partitioning of pollinators among three species of Asclepias. Ecology 64:120-133

Korine C, Kalko EKV, Herre EA (2000) Fruit characteristics and factors affecting fruit removal in a Panamanian community of strangler figs. Oecologia 123:560-568

Krebs CJ (1999) Ecological methodology, 2nd edn. AddisonWelsey Educational Publishers, Inc., Menlo Park

Kwit C, Levey DJ, Greenberg CH (2004) Contagious seed dispersal beneath heterospecific fruiting trees and its consequences. Oikos 107:303-308

Lang FJ, Jokerst JD, Sutter GE (1989) Habitat and populations of the valley elderberry longhorn beetle along the Sacramento River. USDA For Serv Gen Tech Rep PSW-110. Davis, CA

Leishman MR, Wright IJ, Moles AT, Westoby M (2000) The evolutionary ecology of seed size. In: Fenner M (ed) Seeds: the ecology of regeneration in plant communities, 2nd edn. CABI Publishing, Wallingford, pp 31-57

Lepš J, Šmilauer P (2003) Multivariate analysis of ecological data using CANOCO. Cambridge University Press, Cambridge

Levey DJ, Martínez del Rio C (2001) It takes guts (and more) to eat fruit: lessons from avian nutritional ecology. Auk 118:819-831

Lichstein JW, Grau HR, Aragón R (2004) Recruitment limitation in secondary forests dominated by an exotic tree. J Veg Sci 15:721-728

Minor E, Gardner R (2011) Landscape connectivity and seed dispersal characteristics inform the best management strategy for exotic plants. Ecol Appl. doi:10.1890/100321.1 (in press)

Montaldo NH (1993) Dispersión por aves y éxito reproductivo de dos especies de Ligustrum (Oleaceae) en un relicto de selva subtropical en la Argentina. Rev Chil Hist Nat 66: $75-85$

Montaldo NH (2000) Éxito reproductivo de plantas ornitócoras en un relicto de selva subtropical en Argentina. Rev Chil Hist Nat 73:511-524

Moody ME, Mack RN (1988) Controlling the spread of plant invasions: the importance of nascent foci. J Appl Ecol 25:1009-1021

Naeem S, Knops JMH, Tilman D, Howe KM, Kennedy T, Gale S (2000) Plant diversity increases resistance to invasion in the absence of covarying extrinsic factors. Oikos 91: 97-108

Nathan R (2006) Long-distance dispersal of plants. Science 313:786-788

Nel JL, Richardson DM, Rouget M, Mgidi TN, Mdzeke N, Maitre DCL, van Wilgen BW, Schonegevel L, Henderson 
L, Neser S (2004) A proposed classification of invasive alien plant species in South Africa: towards prioritizing species and areas for management action. S Afr J Sci 100:53-64

Panetta FD (2000) Fates of fruits and seeds of Ligustrum lucidum W.T.Ait. and L. sinense Lour. maintained under natural rainfall or irrigation. Aust J Bot 48:701-705

Panetta FD, McKee J (1997) Recruitment of the invasive ornamental, Schinus terebinthifolius, is dependent upon frugivores. Aust J Ecol 22:432-438

Pattison RR, Mack RN (2008) Potential distribution of the invasive tree Triadica sebifera (Euphorbiaceae) in the United States: evaluating CLIMEX predictions with field trials. Glob Chang Biol 14:813-826

Pheloung PC, Williams PA, Halloy SR (1999) A weed risk assessment model for use as a biosecurity tool evaluating plant introductions. J Environ Manag 57:239-252

Pyšek P, Richardson DM (2007) Traits associated with invasiveness in alien plants: where do we stand? In: Nentwig W (ed) Ecological studies, vol. 193, biological invasions. Springer, Germany, pp 97-125

Reinhart KO, Callaway RM (2006) Soil biota and invasive plants. New Phytol 170:445-457

Rejmánek M (2000) Invasive plants: approaches and predictions. Aust Ecol 25:497-506

Rejmánek M, Richardson DM, Pyšek P (2005) Plant invasions and invasibility of plant communities. In: van der Maarel E (ed) Vegetation ecology. Blackwell Science, Oxford, pp 332-355

Renne IJ, Gauthreaux J, Sidney A, Gresham CA (2000) Seed dispersal of the Chinese tallow tree (Sapium sebiferum (L.) Roxb.) by birds in coastal South Carolina. Am Midl Nat 144:202-215

Renne IJ, Barrow WC Jr, Johnson Randall LA, Bridges WC Jr (2002) Generalized avian dispersal syndrome contributes to Chinese tallow tree (Sapium sebiferum, Euphorbiaceae) invasiveness. Div Dist 8:285-295

Rey PJ, Alcántara JM (2000) Recruitment dynamics of a fleshyfruited plant (Olea europaea): connecting patterns of seed dispersal to seedling establishment. J Ecol 88:622-633

Rey PJ, Gutiérrez JE, Alcántara J, Valera F (1997) Fruit size in wild olives: implications for avian seed dispersal. Funct Ecol 11:611-618

Richardson DM, Allsopp N, D'Antonio CM, Milton SJ, Rejmánek M (2000) Plant invasions - the role of mutualisms. Biol Rev 75:65-93
Rollfinke BF, Yahner RH (1990) Effects of time of day and season on winter bird counts. Condor 92:215-219

Sallabanks R (1993) Hierarchical mechanisms of fruit selection by an avian frugivore. Ecology 74:1326-1336

Sargent S (1990) Neighborhood effects on fruit removal by birds: a field experiment with Viburnum dentatum (Caprifoliaceae). Ecology 71:1289-1298

Schoener TW (1970) Nonsynchronous spatial overlap of lizards in patchy habitats. Ecology 51:408-418

Spennemann DHR, Allen LR (2000a) Feral olives (Olea europaea) as future woody weeds in Australia: a review. Aust J Exp Agr 40:889-901

Spennemann DHR, Allen LR (2000b) The avian dispersal of olives Olea europaea: implications for Australia. Emu 100:264-273

Swarbrick JT, Timmins SM, Bullen KM (1999) The biology of Australian weeds. 36. Ligustrum lucidum Aiton and Ligustrum sinense Lour. Pl Prot Q 14:122-130

Thomas L, Buckland ST, Rexstad EA, Laake JL, Strindberg S, Hedley SL, Bishop JRB, Marques TA, Burnham KP (2010) Distance software: design and analysis of distance sampling surveys for estimating population size. J Appl Ecol 47:5-14

Traveset A (1998) Effect of seed passage through vertebrate frugivores' guts on germination: a review. Perspect Plant Ecol Evol Sys 1:151-190

Traveset A, Richardson DM (2006) Biological invasions as disruptors of plant reproductive mutualisms. Trends Ecol Evol 21:208-216

RHJV (Riparian Habitat Joint Venture) (2004) The riparian bird conservation plan: a strategy for reversing the decline of riparian associated birds in California. California partners in flight. http://www.prbo.org/calpif/pdfs/riparian_ v-2.pdf. Accessed 11 Sept 2010

Wenny DG (2001) Advantages of seed dispersal: a re-evaluation of directed dispersal. Evol Ecol Res 3:51-74

Wheelwright NT (1985) Fruit size, gape width and the diets of fruit-eating birds. Ecology 66:808-818

Wheelwright NT, Janson CH (1985) Colors of fruit displays of bird-dispersed plants in two tropical forests. Am Nat 126: 777-799

Whelan CJ, Willson MF (1994) Fruit choice in migrating North American birds: field and aviary experiments. Oikos 71: 137-151

Whittaker RH, Levin SA, Root RB (1973) Niche, habitat, and ecotope. Am Nat 107:321-338 